\title{
Mininge
}

\section{Modelling and Simulation of the Santa Rita Mine Milling Circuit}

http://dx.doi.org/10.1590/0370-44672014690186

\author{
Luiz Tavares dos Santos Junior \\ MSc em Engenharia de Minas, \\ Coordenador de Processos e Desenvolvimento \\ Tecnológico - Mirabela Mineração \\ Itagibá - BA - Brasil \\ luiztsj@yahoo.com.br
}

Professor Doutor

Universidade de São Paulo - USP

Departamento de Engenharia de Minas e de Petróleo

São Paulo - SP - Brasil

hdelboni@usp.br

\section{Homero Delboni Júnior}

Escola Politécnica

\begin{abstract}
The Santa Rita Mine, located in the State of Bahia, was the first Mirabela Mineração operation in Brazil.

Started in 2009, the nickel sulphide processing plant has undergone constant modifications, aiming to adapt to the changes in the ore. Main modifications included autogenous grinding converted to semi-autogenous, as well as the installation of a desliming stage aiming to remove ultrafine minerals which reduced the nickel recovery in flotation.

A full survey and ore characterization campaign was carried out to assess alternatives for increasing grinding circuit capacity. Experimental data were balanced and used to calibrate mathematical models which were the basis for simulation exercises.

This paper describes the main aspects related to circuit modeling and simulation, as well as assessing alternatives for increasing the grinding circuit capacity.
\end{abstract}

Keywords: grinding, simulation, nickel.

\section{Introduction}

Santa Rita is the greatest nickel sulphide discovery in the world in the last 20 years. It was discovered in 2004 and $\mathrm{Mi}-$ rabela Mineração started its operation in

Figure 1

Simplified Flow Sheet of the Processing Plant.

Mined ore is hauled to two primary crushers at an average rate of $1300 \mathrm{t} / \mathrm{h}$. The primary crushing stage product is conveyed to a $67 \mathrm{kt}$ capacity stockpile.

Reclaimed ore is conveyed at 860 $\mathrm{t} / \mathrm{h}$ to the grinding circuit, which includes one SAG mill, two pebble crushers and two ball mills. The grinding circuit is pumped to a desliming stage at a $\mathrm{P}_{80}$ of $125 \mu \mathrm{m}$.
2009. The production was focused on high quality nickel concentrate, with nickel grade varying between $13 \%$ and $15 \%$.

The current processing capacity is 7.2 million $\mathrm{t}$ per year, producing approximately $20 \mathrm{kt}$ of nickel in concentrates. Figure 1 shows a simplified circuit flow sheet.

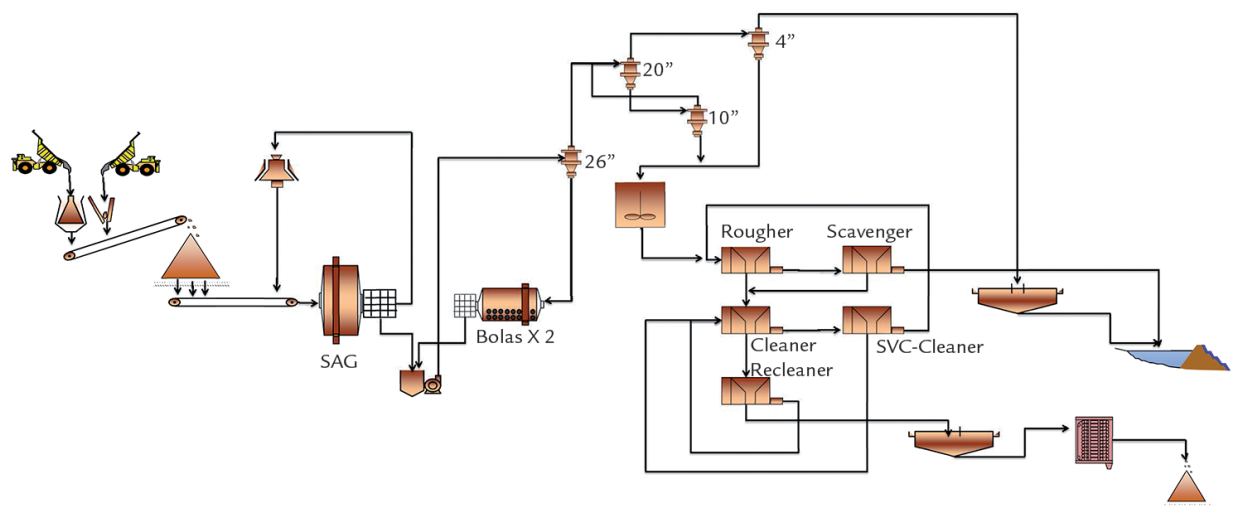

The desliming circuit was not installed in the original processing circuit. However, reduced nickel mineral recovery at flotation stages was observed in the initial operation, which was later associated with fibrous minerals, mainly chrysotile and lizardite, as described by Edwards et al. (1980). It includes three cyclone stages designed to remove such fibrous minerals which are concentrated in fine fractions.
The desliming product is pumped to the concentration circuit, based on the direct flotation of sulphide nickel minerals, together with copper, cobalt and PGM minerals. The metallurgical recovery of the plant is highly variable, depending on the mineralogical characteristics of the processed ore, mainly related to the amount of sulfide and non-sulfide nickel minerals. Global nickel metallurgical recovery 
averages $58 \%$. The final concentrate with nickel grade varying between $13 \%$ and $15 \%$ is thickened and filtered to

\section{Materials and methods}

\section{Industrial Survey Campaigns}

Industrial circuit surveying is the basis for the mathematical modeling and simulation of grinding circuits. Experimental data derived from surveys are initially balanced for providing consistent flowrates and size distribution associated with each single stream around the circuit. Mass balanced data are also useful for assessing circuit performance in terms of both grinding and classification.

Even though it is the basis for any

\section{Ore Characterization}

In this case ore characterization aimed to provide physical, chemical, textural and mineralogical information to allow identifying losses and inefficiencies in the Santa Rita industrial plant.

According to Naschenveng (2003)

\section{Complementary Tests}

Complementary bench tests were carried out so as to better assess specific ore processing aspects.

The first test included determining the fines distribution around the grinding circuit in order to assess the relative amount of natural and generated fines. The former associated with the natural distribution of such minerals in the various ore types, while the latter is related to fines generated in crushing and grinding equipment. The focus on fines was due to chrysotile and lizardite deleterious effects on flotation performance.

Samples from the milling circuit were screened at 8 and $2 \mathrm{~mm}$ sieves. The resulting fractions, i.e. $+8 \mathrm{~mm}-8$

\begin{tabular}{c|c}
$\mathrm{pH}$ & 9.5 \\
\hline $\mathrm{NaOH}(\mathrm{g} / \mathrm{t})$ & 350 \\
\hline $\mathrm{CuSO}_{4}(\mathrm{~g} / \mathrm{t})$ & 40 \\
\hline Citric Acid $(\mathrm{g} / \mathrm{t})$ & 40 \\
\hline $\mathrm{SEX}(\mathrm{g} / \mathrm{t})$ & 60 \\
\hline $\operatorname{DTP}(\mathrm{g} / \mathrm{t})$ & 60 \\
\hline
\end{tabular}

$\mathrm{NaOH}$ is used as $\mathrm{pH}$ modulator. $\mathrm{CuSO}_{4}$ and Citric acid is added as acti-
$9 \%$ humidity.

The optimization study started in the grinding circuit aiming to increase simulation exercise, industrial surveying is generally difficult to be carried out, due to the high flow rates at sampling points and operation stability among other aspects.

The mass balancing exercises are carried out to result in a high fidelity representation of circuit operation. In this case, the grinding circuit sampling was conducted following the criteria proposed by Napier-Munn (1996), so as to reduce the sampling errors described in Gy's theory

in the comminution area, technological characterization is used to assess energy associated to fragmentation, which is used to calibrate mathematical models.

A $150 \mathrm{~kg}$ SAG mill feed sample was separated after homogenization to be sent

$+2 \mathrm{~mm}$ and $-2 \mathrm{~mm}$, were then crushed, ground and floated to assess the respective nickel recovery.

The second bench test aimed to assess desliming alternatives. It consisted in two different processing routes based on SAG mill discharge. The first route included desliming, grinding and flotation, while the second followed the grinding, desliming and flotation sequence. Therefore, the testing program aimed to compare the existing process (second route) with an alternative route, according to which the natural fines would be separated from the secondary grinding stage (ball milling) thus allowing the flotation stage to recover nickel minerals vators and Sodium Etil Xanthate (SEX) and Ditil Phosphate of Potassium (DTP) its capacity, followed by exercises targeting to increase nickel metallurgical recovery in the desliming stage.
(1992). The survey was designed to last one hour. Pulp sampling increments were obtained every 10 minutes, while conveyor belt samples were obtained by removing the respective conveyor belt contents during a crash-stop, the latter conducted after pulp sampling.

A total of 18 different grinding circuit and desliming stage flows were sampled, besides operational and process data of all the equipment involved.

to the Laboratory of Simulation and Control (LSC) of the University of São Paulo.

The sample was used for carrying out standard fragmentation tests such as Bond WI (BWI) and Drop Weight Test (DWT).

contained in the fines.

The third test was based on the work carried out by Senior and Tomas (2005) that showed the benefits associated with staged flotation. The test aimed increasing the nickel metallurgical recovery in flotation by decreasing the losses due to overgrinding. Accordingly, the first flotation stage carried out with relative coarse particles would recover the already liberated nickel minerals which could be over ground in the subsequent grinding stage, thus not recovered in the existing flotation circuit.

The experimental conditions of flotation batch tests are presented in Table 1.
Table 1

Experimental Conditions Flotation Tests.

is used as collectors 


\section{Modelling and Simulation}

The surveyed data were balanced in a JKSimMet simulator. The mass balanced data were the basis for the fitting crushing, milling and classification mathematical models, the latter

\section{Results and discussion}

\section{Ore Characterization}

The Bond WI test carried out on grinding circuit fresh feed resulted in a $21.1 \mathrm{kWh} / \mathrm{t}$ for a $0.150 \mathrm{~mm}$ closing including desliming stages. The characterization tests results were used in all comminution models.

After calibrating the models, a series of simulations were conducted aim- ing to increase the circuit throughput, by adjusting process variables along with modifications in the circuit flow sheet, the latter following the complementary test results. test screen. The result was regarded as an extremely high, according to Delboni Jr. (2003).
The A*b parameter derived from DWT was 46, classified as moderately high, according to Delboni Jr. (2003).

\section{Complementary Tests}

Results obtained from flotation tests carried out on discrete size fractions are listed in Table 2.

Table 2

Natural Fines Results.

\section{Sampling and Modelling}

The sampling program was carried out as planned under steady-state operating conditions. Mass balance exercises

\begin{tabular}{c|c} 
Size Fraction & Ni Recovery (\%) \\
\hline$+8 \mathrm{~mm}$ & 61.7 \\
\hline$-8+2 \mathrm{~mm}$ & 59.2 \\
\hline$-2 \mathrm{~mm}$ & 10.0 \\
\hline Full Sample & 51.3 \\
\hline
\end{tabular}

resulted in relatively low deviations which thus indicate the overall good experimental data quality. Table 3 shows both experimental and respective mass balance results obtained from the selected nine sampling points.
Table 3

Summary of the experimental and balanced data. 
Mass balanced results indicated a relatively low circulating load (163\%) in the ball mills. It also indicated a 21.0 operational WI. According to Rowland (1978) the ratio between laboratory WI and operational WI results in grinding efficiency. Thus, in this case the ball mill grinding circuit resulted in $99.9 \%$ efficiency, which is here considered abnormally high.

Another selected performance index was the by-pass or fine removal in the desliming stage. The calculations indicated a $69 \%$ by-pass of the 0.010 $\mathrm{mm}$ fraction which was here regarded as a very low efficiency.

Model fitting indicated an overall low deviation which thus resulted in a relatively high adherence between balanced and fitted data.

Figure 2 shows SAG and ball mills breakage rates. Note that the curve ex-

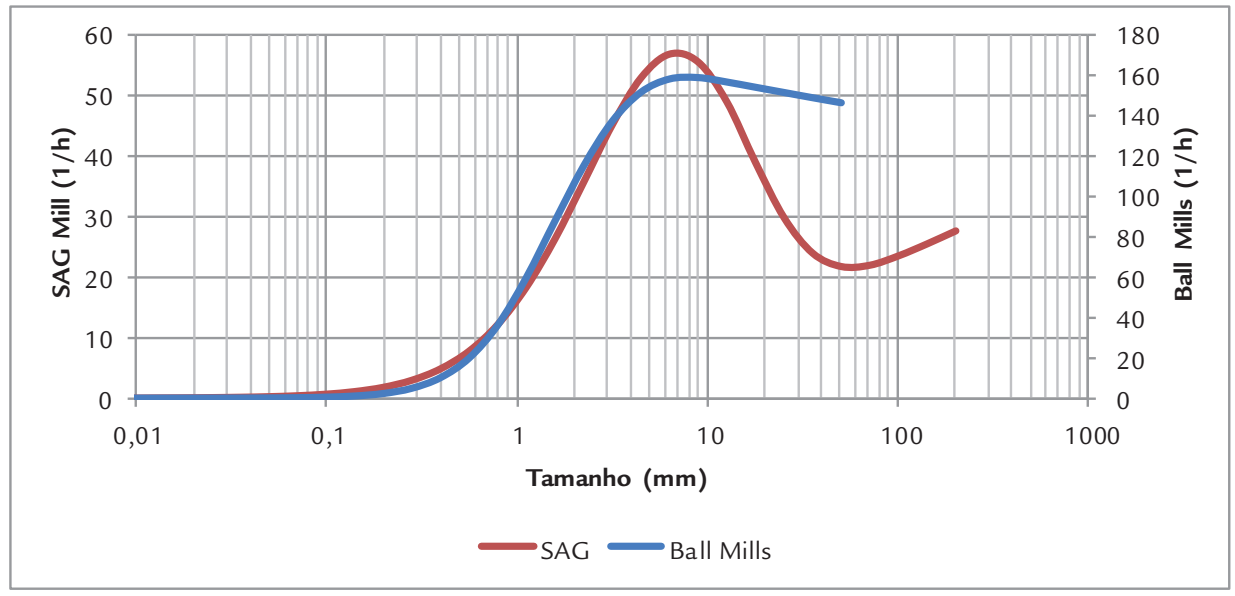

\section{Simulations}

The first simulation set aimed to improve the desliming performance. Simulation 1 consisted in operating the 10 " cyclone cluster in open circuit, diverting its overflow to the tailings, i.e. no longer returning to the 20 " cluster. Simulation 2 included Simulation 1 changes, together with diverting the 4 " cyclone cluster underflow to the 10" cyclone cluster feed.

The fine by-pass was reduced from 69.1\% (Base Case - current operation) to $57.3 \%$ and $44.4 \%$ respectively in Simulations 1 and 2.

The second simulation set explored alternatives to increase grinding circuit throughput. The modifications included (a) increasing the SAG mill ball charge from current $8 \%$ to $12 \%$, as well as (b) reducing the cyclone pulp feed density for the achievement of the stipulated cut size. Such a combination was due to the fact that when increasing the SAG mill ball charge, it grinds coarser, and by reducing the cyclone feed percent solids, it reduces the cut size, thus returning to the original cut size. In such circumstances the circulating load would be increased.

Simulation 4 included changes adopted in Simulation 3, along with (a) reducing the SAG mill ball diameter from 5" to 4", (b) reducing the ball mill ball diameter from 2.5" to 2 " and (c) increasing the ball charge in the ball mills from $27.5 \%$ to $30 \%$. All these modifications aimed to increase the energy consumption in both SAG and two ball mills, which would thus be converted into a higher circuit throughput.

Simulation 4 resulted in a 1070 t/h overall circuit throughput which corresponds to a $29 \%$ increase as compared with the Base Case, while in Simulation 3 the throughput was $975 \mathrm{t} / \mathrm{h}$. Ball mill circulating loads were increased to $200 \%$ in Simulation 4; therefore, higher than the Base Case $0.145 \mathrm{~mm}$. A limiting operation condition was the classification pump volumetric flow rate, limited to $3600 \mathrm{~m}^{3} / \mathrm{h}$.

Based on laboratory flotation test results, two further simulations were carried out by changing the circuit flow sheet. Both targeted increasing $\mathrm{Ni}$ metallurgical recovery.

Simulation 5 was based on test results, which indicated the deleterious effects associated with natural slimes, as opposed to generated fines which showed no reduction in nickel recovery. Hence, the simulation consisted in including a pre-classification figure $(163 \%)$. The same Simulation 4 indicated a grinding product $\mathrm{P}_{80}$ of hibits the classic behavior of a SAG mill curve, showing the effect of the ore as the grinding media in coarse particles and the effect of balls, which begins to appear in the $50 \mathrm{~mm}$ particle size, having its greatest point at $7 \mathrm{~mm}$. For all mills, the breakage rate indicates a profile with a well-defined inflection point. The kinetics is therefore increased for particles up to $6 \mathrm{~mm}$, and decreased for sizes larger than this.

Figure 2

Breakage Rates.

stage after the SAG mill discharge. The pre-classification overflow was thus diverted to desliming stages, while the underflow was directed to flotation.

The results from Simulation 5 showed a 1095 t/h overall circuit throughput, due to the double classification stage prior to ball milling stage.

Simulation 5 also indicated a reduction in slime recovery, from $2.2 \%$ as compared with $8 \%$ of the Base Case.

Simulation 6 considered the twostage ball milling concept, including one flotation stage between the two milling stages, as well as one after the second ball milling stage. The strategy here was to reduce $\mathrm{Ni}$ mineral overgrinding and therefore the $\mathrm{Ni}$ losses in flotation. In other words, the two existing parallel ball mills would be converted to an operation in series. Simulation 6 was based on the changes included in Simulation 5.

Simulation 6 results showed $1050 \mathrm{t} / \mathrm{h}$ circuit throughput, yielding $0.213 \mathrm{~mm}$ and $0.138 \mathrm{~mm}_{80}$ values respectively at first and second ball milling stage discharges.

Simulation exercise results were used to calculate the respective nickel production based on laboratory flotation tests. The results are listed in Table 4. 


\begin{tabular}{cc|c|c|c|c} 
& Scenario & $\begin{array}{c}\text { New Feeding } \\
(\mathrm{t} / \mathrm{h})\end{array}$ & $\begin{array}{c}\text { Ni Content } \\
(\%)\end{array}$ & $\begin{array}{c}\text { Global Ni Recovery } \\
(\%)\end{array}$ & $\begin{array}{c}\text { Ni Production } \\
(\%)\end{array}$ \\
\cline { 2 - 6 } & Base Case & 830 & 0.52 & 47.2 & 2.04 \\
\hline & Simulation 3 & 975 & 0.52 & 47.2 & 2.39 \\
\hline & Simulation 4 & 1070 & 0.52 & 47.2 & 2.63 \\
\hline Table 4 & Simulation 5 & 1095 & 0.52 & 51.2 & 2.92 \\
\hline
\end{tabular}

The highest nickel recovery was derived from the two-stage milling option with two flotation stages

\section{Conclusions}

The survey campaign planning and sampling techniques were considered adequate as mass balance indicated low deviations between experimental and balanced results. The latter were successfully used for modeling the entire comminution circuit, together with the desliming stage, thus creating a Base Case.

The Base Case assessment of operation performance indicated a low circulating load in the ball milling stage, as well as very low efficiency in the desliming stage. Laboratory batch tests indicated
(Simulation 6). However, the highest nickel production was obtained for the anticipated desliming stage. The obtained figure $(2.92 \%)$ was $43 \%$ higher than the Base Case (2.04\%). a great potential for improving the nickel global recovery by relatively simple changes in the current process flow sheet. Accordingly, a desliming stage after SAG milling would prevent significant losses in nickel contents, as compared with current desliming after the ball milling stage. Staged ball milling and flotation would also enhance significantly the overall nickel metallurgical recovery.

In the desliming circuit, a better performance would be achieved by operating the 10" cyclone cluster in open circuit, diverting its overflow to the tailings, ie. no longer returning it to the 20 " cluster.

Increasing ball mill charge, along with adjusting the percent solids in classification feed, resulted in significant increase in the circuit overall throughput.

Modelling and simulation were considered decisive tools for both assessing and improving circuit performance of the Santa Rita concentrator. The simulations indicated potential benefits to enhance nickel recovery and production, thus providing support for decision-making.

\section{Acknowledgements}

The authors wish to thank Mirabela Mineração especially Mr. Evandro Faria for supporting this study.

\section{References}

DELBONI JR, H. Modelagem e simulação de circuitos de cominuição e classificação. São Paulo, Escola Politécnica, 2003. (Apostila do Curso PMI 5004).

EDWARDS, C.R., KIPKIE, W.B., AGAR, G.E. The effect of slime coatings of the serpentine minerals, chrysotile and lizardite, on pentlandite flotation. International Journal of Mineral Processing, Amsterdam, v. 7, n.1, p. 33-42, 1980.

GY, P.M. Sampling of heterogeneous and dynamic material systems: theories of heterogeneity, sampling and homogenizing. Amsterdan: Elselvier, 1992. 653p.

NAPIER-MUNN, T.J. et al. Mineral comminution circuits: their operation and optimization. Indooroopilly, SMIJKRMC, 1996. 413 p.

NASCHENVENG, A.C. Modelagem e simulação do circuito de moagem da Ultrafértil. São Paulo: Escola Politécnica, Universidade de São Paulo, 2003. 101 p. (Dissertação de Mestrado).

ROWLAND, C.A. Determination and use of operating work indices in controlled grinding circuits - a proposed concept. In: MILL OPERATOR'S CONFERENCE, 1978. North West Queensland Branch. Papers presentedat the Mill Operator's Conference. Parkville: Australasian Institute of Mining and Metallurgy, 1978, p.71-78.

SENIOR, G.D; THOMAS, S.A. Development and implementation of a new flowsheet for the flotation of a low grade nickel ore.International Journal of Mineral Processing, Amsterdam, v. 78, n.1, p 49-61, 2005. 